\title{
Analysis of China Populism in the Context of New Media Development
}

\author{
Guannan $\mathrm{E}^{1, \mathrm{a}}$ and Jing $\mathrm{Yi}^{2, \mathrm{~b}}$ \\ ${ }^{1}$ Beijing Institute of Fashion Technology, China \\ ${ }^{2}$ Beijing Film Academy, China \\ ajoye_bift@126.com, ${ }^{b}$ yijing_1994@126.com,
}

\begin{abstract}
Keywords: Populism; New Media; Communication
\end{abstract}
\begin{abstract}
The concept of populism has had a long history. It is a political ideological trend, social movement and cultural mentality with historical recurrence. And it presents different characteristics in different historical development periods. The new media technology is different from traditional media experience, its characteristics of openness, equality, interaction has broken the traditional media of the line between the communicator and the receiver, and broke the time and space constraints. As an emerging public communication means, the new media decomposes the monopoly of right of speech in the view of traditional media effectively, and provides a feasible platform for the civilians. This paper starting from the populism and cutting in from the perspective of the communications, discuss the basic features of the populism in new media context, and try to explore the path of constructing a harmonious and pure new media environment in China.
\end{abstract}

\section{Introduction}

The occurrence of populism has a long history. Ever since Russia and America created the leading practices of populism in the slogan of "going to the people" and organization of People's Party movement in the middle of the 19th century, populism started to rise in every corner of the world, presenting evident historical recurrence. Populism is an extreme thought or movement strengthening on the value of the masses, and it shows the extreme promotion of the public and the strong resistance to elites, which is characterize by typical populism or anti-elite color. Therefore, "plebification" and "worship of people" turns to be the recognized label of populism naturally. Populism is filled with critical spirit and rebellion consciousness to a certain degree, and its pattern of manifestation is diversified, which can be a political thought, or a social movement, or even a cultural attitude.

The technological development would certainly bring the reform in media. Compared to the traditional media, like the newspaper, broadcast, television, etc. the new media can spread throughout the world in its unique advantages. The openness, equality and interaction of new media provides convenient channels for the expression of the public opinion, and the masses can publish their opinions and express their appealing aiming at the news information, social hotspots, etc. through the platform provided by new media. More and more people have participated in the discussion of social hotspots, and the enthusiasm of supervision by public opinions boots. However, the non-rationality and criticalness of people is hiding behind the supervision by public opinions, which happen to hold the same view with the populism. In the constant development and expansion of new media, populism seems to find new dwelling space, and the freedom and opening of new media provides appropriate soil for the derivation and changes of populism.

\section{Potential changes of populism in the new media development}

\subsection{Participation platform: form single to multiple}

\subsubsection{Populism in the view of traditional media: singleness of platform}

The spreading of populism thought mainly relies on the support of media, but due to the limits in technical conditions, the early information spreading form was relatively simple, and it was also the 
same for communication platform. All kinds of information communication systems were independent from each with, with poor interaction and few options. Besides, it was mainly limited to the newspaper, magazine, broadcast and television, etc. presenting a simple participation mode.

In the 1870s, the populism movement rose in Russia. A batch of noble youth with high political consciousness realized the plight of Russia, gathered with some civilian young intellectuals spontaneously, and boarded on the political stage of Russia on behalf of the farmers' bourgeoisie interest. Due to the summoning and impact of Hull's idea of "coexisting with people”, a populism movement with the slogan "going to the people" was raised. They dressed in farmer's clothes, crossed mountains and rivers to talk face to face with farmers from one village to another, advertised the significance of revolution, passed on the important spirit of movement, and called on the farmers to resist the ruling by tsar. Although such oral communication spread the thought of populism to a certain degree, it was time-consuming and effort-consuming.

\subsubsection{Populism in new media context: diversity of platform}

With the constant development and innovation of new media technology, the information spreading channels become more and more diversified. From the original BBS, email, web portals to instant messaging software, such as QQ, MSN, etc. to the emerging places of public opinions, such as the blog, podcast, social website, Weibo, Wechat, etc. the internet presents a grand social interaction platform with extensive options. The occurrence and flourishing of new media change the traditional communication interaction mode. The boundary between the spreaders and receivers in the previous information communication process was quitting distinct, but the individual characteristics are quite vague. In a specific interpersonal communication mode, the spreader is entirely different from the receiver, and there won't be overlaps. The core characteristic of new media age shall be the de-centration of the communication subject, in which everyone can be the spreader and receiver of information, and the spreader and receiver can reach the unification in a certain sense. Moreover, the convenience and civilian of new media may become the hotbed of the populism.

\subsection{Participation subject: from elites to grassroots}

\subsubsection{Populism in the visual threshold of traditional media: manipulation of elites}

The concept "populism" contains the specific relation between the elite and civilian. Superficially, the populism is extremely particular about the civilian, by advocating the public democracy, all-people participation and the majority of ruling, with strong anti-elite tendency. However, the relation between the two is not so simply. Actually, the elitism is also the dark current in the populism. In the early stage, the populism was represented as the elitism regarding the public as the ruling tool or political strategy.

\subsubsection{Populism in new media context: rise of grassroots strength}

The development and maturity of new media technology makes the production and release of information content much simpler and more convenient. The openness, equality and interactive features of the new media platform break the differences in the identity, class and social status of the communication subjects in the realistic world, as well as the monopoly of elites right of speech in the mainstream ideology and traditional media. According to the data of the 39rd Statistical Report of the Development Status of Internet in China, till the end of December 2016, the number of netizens reached 751 million, equivalent to the total population of Europe. Internet penetration reached 53.2\%, with 700 million mobile Internet users and $95.1 \%$ of mobile Internet users. (Figure 1)

As an emerging public communication means, the new media decomposes the monopoly of right of speech in the view of traditional media effectively, and provides a feasible platform for the civilians. Civilians become the active dominant force on the new media platform, eliminate the elites' monopoly in the right of speech in traditional significance, and realize the democracy in right of speech in real sense. 
Figure 1: The size and penetration rate of Chinese Internet users in 2008-2016

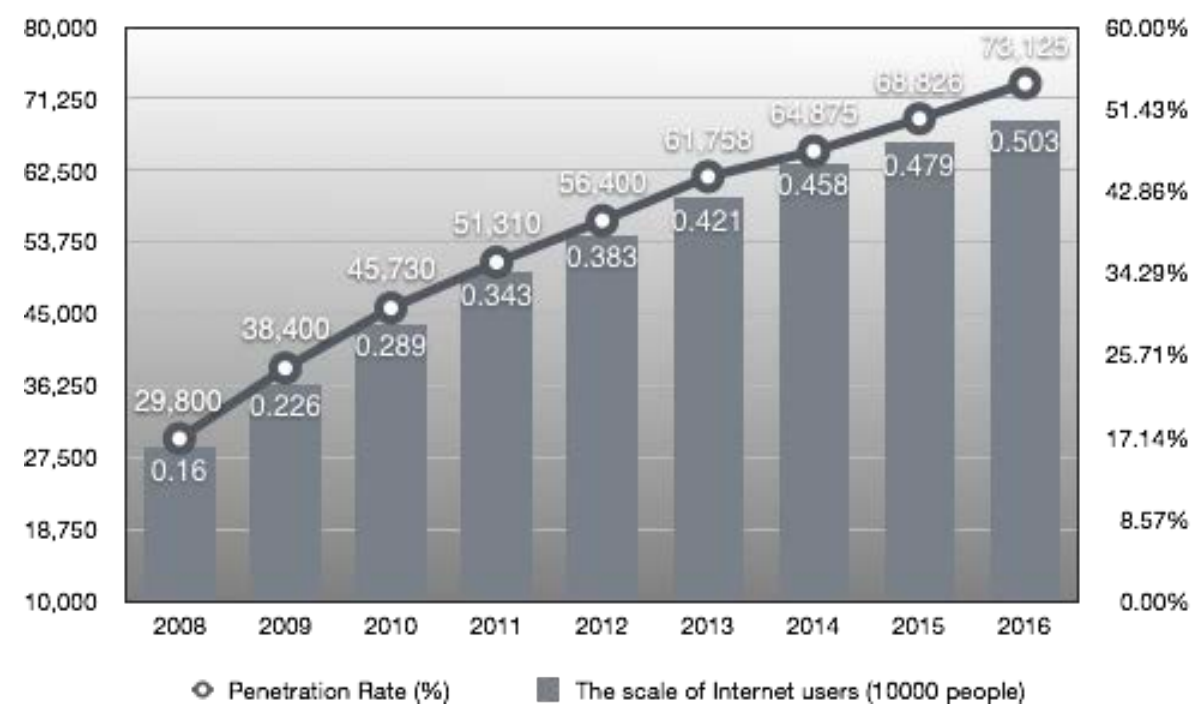

\section{Cyber Populist: Effect of populism in the context of new media}

Although populism is a relatively complicated phenomenon, its core element is always the same, namely emphasizing the value and ideal of the public, and opposing the elite and authority. The emergence and development of new media provides a more open and free communication platform for populism. The potential changes of populism in new media context are reflected in all aspects. We shall take the social effect generated by populism dialectically, both the positive effect and negative effect. On one hand, it pays a lot of attention to the vulnerable group, and provides a solid foundation for the implementation of the discursive democracy of the public, and the extensive participation of the citizens also offers reliable guarantee for the social supervision. On the other hand, the irrational public opinions may result in the polarization of group, and the excessive attention to the social case may disturb the normal procedures and judicial systems.

\subsection{Positive effect of populism in new media context}

The positive effect of the populism in new media context is mainly from the grassroots and criticism features of populism, namely it always emphasizes the value and ideal of the civilian, focus on the interest of the civilian and vulnerable group, opposite the elitism, full of criticism spirit and resisting consciousness. The positive effect of populism in new media context is mainly reflected in the supervision of the elites and authority and the focus on the vulnerable group. It will be favorable for eliminating the monopoly in right of speech of the elite class in traditional media, as well as the effective realization of the discursive democracy of the citizens.

\subsubsection{Social supervision: constraint over the elite and authority}

The denial and criticism of the current political system, national system and elite authority is the specific connotation of the critical features of populism. The populism is mainly reflected by the attention to the interest and value of the vulnerable group, and the criticism of the speech and behavior of the strong power. The intellectuals, officials, merchants, with certain social relations and background belong to the strong group in the society, which grasp more political, economic, and cultural resource, as well as the absolute right of speech. However, the rapid development and rise of the new media breaks the boundary between the spreader and receiver, and offers an equal and free speech space, so that everyone can become the spreader, and publish his opinions of views equally and freely. The instantaneity and richness of the information communication allows the citizens to update the information in time, and learn about all aspects of social life. The elite 
authority presents a "naked" trend, and their actions and speeches are exposed in public, which is quite favorable for the supervision and criticism by the public.

\subsubsection{Discursive democracy: attention to the civilian and vulnerable group}

One of the typical features of populism shall be the grassroots feature, namely it emphasizes the value and ideal of the public extremely, stresses the direct participation in the politics, and pays attention to the interest of vulnerable group. Due to the insufficient resources, capabilities and quality, etc. the bottom public cannot grasp the right of speech, and as a result, the right of speech is gradually monopolized and controlled by the elite class, forming the hegemony in the right of speech. In the view of traditional media, the participation right, right to know and right of speech may be limited by space and time, etc. which may make it difficult to transmit, spread and even feed back the opinions and suggestions of the citizens. However, the development and flourishing of new media technology brings brand new and equal media communication platform for citizens. The discourse hegemony in traditional sense is finally eliminated, and the citizens can express their opinions freely and equally on the new media platform, thus to realize the discursive democracy in real sense.

\subsection{Negative effect of populism in new media context}

The negative effect produced by populism in new media context is mainly from the irrational and critical features of the populism, namely it is reflected by the emotion-first trend by relying on the spiritual strength and moral calling. It implies the criticism of rationalism and promotion of morality ideals, and reflects the irrational collective logic. The negative effect of populism in new media context is mainly reflected by the flooding irrational public opinions, and disturbance and damage to the judicial justice. For the disturbance of the flooding irrational public opinions to the judicial justice, the new media platform may be filled with the irrational and emotional opinions, which may form the group polarization phenomenon, which is not favorable for the social stability and harmony. On the other hand, the integration and expansion of the criticism of citizens may result in the far-reaching social impact and form a huge pressure from public opinion, which may disturb and even damage the judicial justice to a certain degree.

\subsubsection{Group polarization: flooding irrational public opinions}

Mentally, the populism is the expression of group emption, and it is the rebellion and mania against the current system and status out of the extreme desire of human, such as the justice, equality, participation, simplicity, etc. It relies on the spiritual strength and moral calling, reflecting a kind of irrational collective actions and logic. The open space of the new media context provides comfortable hotbed for the gathering of irrational emotions. Aiming at a certain social hotspot, the public may express aggressive, critical and provocative speeches through the new media platform. With the calling of such emotions, the group members usually gathered irrationally, and the rational voice may be attacked in the gathering and then buried, and finally forming the group popularization phenomenon.

\subsubsection{Judicial interference: disturbance and damage to the judicial justice}

The development and popularity of new media technology brings brand new speech space for citizens. The anonymity, openness, and equality of network, etc. shorten the distance between the citizens and the government. In recent years, the political affairs Weibo begin to get popular, and it is the heroic undertaking for being transparent and close to the public, which may zoom in the interaction between the governmental departments and citizens, and be favorable for the effective implementation of the participation right, right to know and supervision right. In the judicial case hearing process, the public may usually analyze the case at the height of moral judgment based on the perceptual knowledge, and publish their opinions and views on the new media platform. But these opinions may be covered with the populism color, and inconsistent opinions may be repelled, for expanding the group team and forming great pressure from public opinions. As a result, it may 
result in strong social impact and bring great disturbance to the judgment on the crime by the judicial offices.

\section{Conclusion}

The development of populism in new media context has already become irresistible, and the open and convenient new media platform provides effective channels for the discussion and evaluation of the social hotspots. Recently, many common social events turn to be the hotspots due to people's extensive attention and active participation, and the realistic society is moved into the virtual network world. People started to show their opinions freely in the open and anonymous new media environment, seek for similar or the same group of "information cocoon", and then dominates the peak of public opinion with a gradually expanding populism trend.

Every coin has two sides, and it also has no exception for the populism in new media context. On one hand, it can help supervise and restrain the elite rank and authority organ, for the open discursive environment may be favorable for the implementation of discursive democracy, and it is a significant reflection of the social fairness. On the other hand, the excessive participation in the social events may interfere in and disturb the judicial fairness. If the new media platform is filled by the irrational voice, it may result in too much unreasonable public opinion information, and reach the polarization degree. Meanwhile, we shall give full play to the positive effect, and make full use of the social supervision function, to realize the supervision and restrain of authority in realistic society, and promote the social fairness and national harmony. As for the negative effect, we shall also understand it reasonably, establish effective network supervision and management system, improve the comprehensive quality, strike the violence and unreasonable voice severely, promote the development of public opinion to a healthy and orderly directly, thus to lay a solid foundation for the construction of a harmonious and pure new media environment.

\section{Acknowledgement}

In this paper, the research was sponsored by the National Social Science Fund of China (Project No. 16ZD04).

\section{References}

[1] Abts K, Rummens S. Populism versus Democracy[J]. Political Studies, 2007, 55(2):405-424.

[2] Bimber B. The Internet and Political Transformation: Populism, Community, and Accelerated Pluralism[J]. Polity, 1998, 31(1):133-160.

[3] Boyte H C. The Populist Persuasion: An American History. by Michael Kazin[J]. 1996, 82(4):1594.

[4] Chen long. The discourse monopoly strategy of Internet populism [J]. Journal of Suzhou University, 2011(6):157-162

[5] Laclau E. On populist reason[J]. Verso, 2005.

[6] Li Liang-rong, Xu Xiaodong. The Internet and the populist popular - new communication revolution series [J]. Modern communication - journal of China media university, 2012, 34(5):26-29.

[7] Jiang hua. Global news populism: origins and social impact [J]. Journalist, 2015(11):21-30.

[8] Mcguigan J. Cultural Populism. [M]// Cultural populism. Routledge, 1992.

[9] Yongnian Zheng, Guoguang Wu Information Technology, Public Space, and Collect ive Action in China. Comparative Politics. 2005 
[10] Tai Z. The Internet in China: Cyberspace and Civil Society[M]. Routledge, 2012. 